\title{
REESTRUTURAÇÃO PRODUTIVA E DIVISÃO SEXUAL DO TRABALHO NA AGROINDÚSTRIA CANAVIEIRA
}

\author{
Juliana Biondi Guanais*
}

\begin{abstract}
Resumo: O presente trabalho tem como objetivo principal analisar os motivos que levaram as trabalhadoras assalariadas rurais a serem progressivamente excluídas do trabalho no corte da cana na agroindústria canavieira brasileira. Historicamente as mulheres sempre foram empregadas para trabalhar como cortadoras de cana, mas sobretudo dos anos 2000 em diante - momento em que o setor sucroalcooleiro passou por um processo de reestruturação produtiva - parcela expressiva da força de trabalho feminina passou a perder seus postos de trabalho no setor em função dos novos critérios para o recrutamento e para a seleção dos trabalhadores.
\end{abstract}

Palavras-chave: assalariadas rurais; agroindústria canavieira; reestruturação produtiva; divisão sexual do trabalho; discriminação.

Productive restructuring and sexual division of labor in the sugarcane agribusiness

Abstract: This study aims to analyze the reasons why rural workers have been gradually excluded from the work of cutting cane agribusiness in the Brazilian sugarcane. Historically women have always been used to work as cane cutters in the plantations of sugar cane in Brazil, but especially from the 2000s onwards, due to production restructuring process through which passes agribusiness, important part of the female workforce lost their jobs in the sector according to the new criteria for the recruitment and selection of workers.

Keywords: rural salaried; sugarcane agribusiness; productive restructuring; sexual division of labor; discrimination.

\footnotetext{
* Doutora pelo do Programa de Pós-graduação em Sociologia do Instituto de Filosofia e Ciências Humanas da UNICAMP. Pesquisadora do Centro de Estudos Rurais (CERES) da mesma instituição. Email: guanaisjuliana@gmail. com. Parte deste artigo foi publicada em espanhol na Revista Entreciencias: diálogos en la sociedad del conocimiento (México, abril de 2014).

Recebido em: 15/11/2015 - Aceito em: 13/04/2016.
} 
Reestruturação produtiva e divisão sexual do trabalho...

Reestructuración productiva y división sexual del trabajo en la agroindustria de caña de azúcar

Resumen: Este artículo analiza las razones por las cuales las trabajadoras rurales han sido excluidas gradualmente de la tarea del corte de caña en la agroindustria cañera brasileña. Aunque históricamente las mujeres han sido cortadoras de caña de azúcar, a partir del año 2000 - debido al proceso de reestructuración productiva de la agroindustria - parte importante de la fuerza de trabajo femenina perdió su lugar en el sector debido a los nuevos criterios para contratación y selección de los trabajadores.

Palabras clave: jornaleras agrícolas; agroindustria de caña de azúcar; reestructuración productiva; división sexual del trabajo; discriminación.

O presente trabalho tem como objetivo principal analisar os motivos que levaram as trabalhadoras assalariadas rurais a serem progressivamente excluídas do trabalho no corte da cana na agroindústria canavieira brasileira. Como é sabido, historicamente as mulheres sempre foram empregadas para trabalhar como cortadoras de cana nas lavouras de cana de açúcar (SILVA, 1999; D'INCAO, 1976), mas sobretudo dos anos 2000 em diante - momento em que o setor sucroalcooleiro passou por um processo de reestruturação produtiva - parcela expressiva da força de trabalho feminina passou a perder seus postos de trabalho no setor em função dos novos critérios para o recrutamento e para a seleção dos trabalhadores. Como veremos, é nesse contexto em que não somente as mulheres, mas também os trabalhadores de idade mais avançada passaram a ser progressivamente excluídos do trabalho no corte da cana pelo fato de apresentarem índices de produtividade mais baixos que os demais trabalhadores - na sua grande maioria jovens do sexo masculino - tidos pelas usinas como os mais capacitados fisicamente para aguentar o trabalho no corte da cana e atingir as novas metas de produção impostas, cada vez maiores.

É necessário mencionar que o artigo em questão toma como base duas pesquisas: a realizada entre 2008 e 2010 junto à Usina Açucareira Ester S.A. (localizada em Cosmópolis-SP); e a realizada entre 2011 e 2013 junto às usinas Costa Pinto e Furlan (localizadas, respectivamente, em Piracicaba e Santa Bárbara d'Oeste-SP). Além das entrevistas com os(as) trabalhadores rurais, também foram 
entrevistados seis fiscais de turma (agentes fiscalizadores das usinas) e dois presidentes de sindicatos rurais.

Como ficará claro na exposição, no que se refere especificamente à situação das mulheres assalariadas rurais, ainda que nossa pesquisa de campo guarde algumas singularidades quando comparada à desenvolvida por outros pesquisadores da área (SILVA, 1999 e 2011a e b; BUENO, 2011), os resultados gerais obtidos se aproximam e vêm a corroborar aqueles já divulgados por pesquisas anteriores, tais como as de Maria Aparecida de Moraes Silva (1999 e 2011a e b).

Como já demonstrado em outras ocasiões (GUANAIS, 2010), ao longo de seu desenvolvimento no Brasil, o setor sucroalcooleiro passou por vários processos de reestruturação que atingiram, sobretudo, as plantas industriais e seus equipamentos (IANNI, 1984). Mas foi a partir da década de 2000 que a reestruturação produtiva sucroalcooleira atingiu também o setor administrativo das empresas, especialmente a gestão do trabalho.

Desde o final do século XX a reestruturação buscou tornar os empresários cada vez mais aptos para enfrentar as novas regras de produção e de circulação impostas principalmente pelo mercado internacional, as quais estavam centradas, sobretudo, no incremento da produtividade e na redução dos custos de produção (SCOPINHO, 2000; 2004). Assim, para que fosse possível atender as novas exigências de produtividade impostas pelo mercado, as usinas redefiniram suas estratégias administrativas e no bojo deste processo modificaram bastante os critérios para a seleção de sua força de trabalho. Isso fez com que o setor em questão passasse a operar com critérios diferenciados para selecionar seus funcionários, elaborando perfis adequados para funções determinadas.

Com a introdução dos novos arranjos produtivos as usinas passaram a exigir maior produtividade e mais disciplina no 
trabalho. Ao mesmo tempo, provocaram uma segmentação maior da força de trabalho, intensificaram a precarização e imprimiram uma nova dinâmica na seleção de seus trabalhadores. Nas palavras de Novaes (2007):

\begin{abstract}
Nesse processo, as usinas vão formando grupos de trabalhadores seletos, os super-homens da produção, os campeões de produtividade (...) Contudo, para entrar nesse grupo seleto, é preciso cortar no mínimo dez toneladas/dia. No novo perfil de trabalhadores para o corte manual da cana, como visto anteriormente, a força e a resistência física são critérios eliminatórios (...) Consequentemente, idade e gênero passam a ter grande importância na seleção dos trabalhadores para o corte manual da cana (NOVAES, 2007: 97).
\end{abstract}

Assim, para que fosse possível formar esse "grupo seleto" de trabalhadores as usinas passaram a excluir não somente aqueles que não atingiam as metas de produtividade, mas sobretudo as mulheres ${ }^{1}$. Importante mencionar que essa tendência está na contramão do que ocorria até pouco tempo atrás. Como sabemos, a partir da década de 1970 - devido aos subsídios do governo brasileiro para a implantação do Pró-Álcool em 1975 - o setor sucroalcooleiro passou por um processo de expansão crescente. Assim, para que fosse possível aumentar a produção de álcool exigida pela nova demanda, esse tipo de cultivo agrícola passou a

\footnotetext{
${ }^{1}$ A exclusão das mulheres dos postos e dos setores de trabalho que sempre ocuparam não é exclusividade do meio rural. De acordo com ARAÚJO (2009), "Estudos recentes têm mostrado a ocorrência de uma migração compulsória das mulheres de grandes empresas formais, em diversos setores da economia e particularmente da indústria, para atividades informais, pequenas empresas prestadoras de serviços, trabalho domiciliar ou cooperativas de trabalho (...) Tais estudos confirmam que nos processos de enxugamento de postos de trabalho nas grandes empresas, as mulheres foram sendo paulatinamente deslocadas 'dos setores e ocupações que sempre marcaram presença', assim como 'de atividades industriais de grande porte, para pequenos e médios estabelecimentos"' (ARAÚJO, 2009: 139).
} 
necessitar de um número cada vez maior de trabalhadores rurais. Como resultado de todo esse processo, principalmente a partir da década de 1970 as plantações de cana de açúcar de todo o estado de São Paulo passaram a empregar uma quantidade expressiva de homens e também de mulheres nos canaviais. Naquela época, além de exercerem a mesma função - o corte de cana - ambos os sexos também trabalhavam lado a lado nos canaviais.

Em seu estudo D'incao (1976) faz questão de destacar que inclusive nas décadas de 1960 e 1970 a maioria dos trabalhadores temporários (também conhecidos como "volantes", "sazonais" ou "boias-frias") era composta por mulheres e homens com idade superior a quarenta anos, ao passo que os mais jovens, sobretudo do sexo masculino, eram preferidos para ocuparem os postos de trabalho urbanos. Hoje verificamos exatamente o contrário na agroindústria canavieira. Maria Aparecida de Moraes Silva (1999) nos explica assim esse processo:

A produção da figura do "bom cortador" contém germes de uma verdadeira segmentação do emprego de homens, fortes, jovens (...) Os fracos, os mais velhos, as mulheres são descartados deste modelo (...) a fabricação do "bom cortador" não é só para cortar cana, mas se trata de um "sujeito moral", de um trabalhador cujo corpo e espírito estão dotados dos elementos necessários à execução das tarefas (SILVA, 1999: 206).

E em seguida a autora conclui:

Ao corte, são destinados, prioritariamente, os mais jovens, dotados de maior força para o trabalho (...) O arrebanhamento destas "cabeças" leva em conta os seguintes critérios: as mulheres não são aceitas; os homens acima de 35 anos também não são aceitos, assim como os "maus", aqueles que criam encrencas (SILVA, 1999: 207). 
Neste contexto em que a produtividade passou a ser o critério mais importante para a seleção daqueles (as) que vão trabalhar nas usinas, não somente aqueles trabalhadores que não atingiam as metas de produção impostas, mas sobretudo as mulheres e os trabalhadores de mais idade foram sendo progressivamente excluídos $^{2}$. Para viabilizar esse processo de reorganização do quadro de funcionários, o setor sucroalcooleiro passou a instituir diversas estratégias empresariais, dentre elas a "média"3, isto é, a imposição de uma produtividade diária mínima que deve ser atingida pelos trabalhadores caso desejem manterem-se em seus postos de trabalho. Ao não conseguirem atingir a "média" diária estipulada pela usina para qual trabalham, os cortadores de cana são demitidos. Necessário mencionar que com o passar dos anos, a "média" teve um aumento considerável, passando de 5 a 8 toneladas em 1980 para 12 a 15 toneladas em 2004 (SILVA, 2006), fazendo com que todos os trabalhadores fossem obrigados a aumentar a intensidade de seu trabalho e a quantidade de cana cortada por dia para que pudessem permanecer na usina para qual trabalhavam.

\footnotetext{
${ }^{2}$ Importante mencionar aqui que esse tipo de seleção da força de trabalho é ainda mais facilitado devido à forma de remuneração dos cortadores de cana - o pagamento por produção - que atrela o salário de cada trabalhador(a) à quantidade de cana cortada pelo(a) mesmo(a) ao longo de sua jornada de trabalho. Assim, como cada trabalhador(a) recebe pelo que produz, ao comparar os salários de todos os empregados, torna-se fácil para as empresas descobrirem quais são aqueles(as) que cortam mais cana, e quais são os(as) que menos cortam. Esta seleção por produtividade é bastante importante para as usinas, que assim podem manter em seu quadro de funcionários somente aqueles(as) cortadores(as) de cana que lhe interessam - os(as) que são os(as) mais produtivos(as) - e demitir todos(as) aqueles(as) que não conseguem atingir os índices de produtividade previamente estipulados.

${ }^{3}$ Medida em toneladas de cana. Trata-se da quantidade mínima de toneladas de cana que deve ser cortada diariamente por cada trabalhador e que serve de referencial para a produtividade dos mesmos. Para mais informações sobre a "média" ver: Silva (1999 e 2006) e Alves (2006).
} 
No caso específico das mulheres, pelo fato de serem consideradas pelos usineiros (e também pelos fiscais de turma) menos fortes e resistentes fisicamente do que os homens, além de "inaptas" para o desempenho desse tipo de "trabalho pesado", não eram vistas como capazes de atingir os altos índices de produtividade impostos, e por isso deveriam ser dispensadas. Assim, para ocupar o lugar das mulheres e dos demais excluídos do trabalho no corte da cana, as empresas passaram a optar principalmente por trabalhadores do sexo masculino, jovens e migrantes de outras regiões, tidos como os mais capacitados fisicamente para aguentar o trabalho no corte da cana e atingir as metas de produção impostas.

Em pesquisa anterior, realizada entre 2008 e 2010 (GUANAIS, 2010), foram entrevistadas algumas poucas mulheres que ainda trabalhavam como cortadoras de cana para a Usina Ester (Cosmópolis-SP). Naquela ocasião, as trabalhadoras relataram que seus índices de produção eram baixos, sobretudo quando comparados aos índices de seus colegas de trabalho. Isso as tornava as maiores candidatas a serem demitidas pela usina, o que somente não ocorria porque elas podiam contar com o respaldo do sindicato que representava os assalariados rurais, situação esse diferente da apresentada em outros estudos, tais como os de Maria Aparecida de Moraes Silva (1999 e 2011a).

O sindicato em questão sabia que, devido aos novos critérios de seleção dos trabalhadores - baseados quase que exclusivamente nos índices de produtividade dos mesmos - se dependesse das usinas as mulheres seriam totalmente excluídas do trabalho no corte da cana. Assim, para tentar assegurar pelo menos uma pequena parcela da força de trabalho feminina na referida usina, o sindicato exigiu que a empresa mantivesse pelo menos 10 mulheres cortadoras de cana para cada turma de 40 homens. Devese ressaltar aqui que, por mais bem intencionada que pode ter sido, tal medida só garantiu a permanência efetiva de algumas poucas mulheres no corte de cana, já que, com a exceção deste grupo remanescente de mulheres, todas as demais foram demitidas. 
Mas mesmo conseguindo assegurar sua vaga na usina para qual trabalhavam, as poucas mulheres cortadoras de cana se queixavam dos baixos salários recebidos, na grande maioria das vezes insuficientes para arcar com todos os gastos que tinham. De acordo com Maria ${ }^{4}$, uma das entrevistadas, pelo fato de receber por produção e por ser uma cortadora de cana que tinha índices de produção muito aquém dos demais, seu salário mensal acabava sendo sempre muito baixo. "Hoje [em 2008] eu não recebo nem setecentos reais por mês...".

Outro aspecto interessante foi levantado por Ana, outra cortadora de cana:

O pagamento por produção favorece mais os mais jovens, né, que tão começando a trabalhar agora e que tem o corpo novo. E os homens também. Esses têm mais força e aguentam mais que nós, mulher. Pra cortar muita cana é melhor ser forte, por isso que os homens cortam mais (Ana).

De acordo com a trabalhadora, quando a atividade do corte da cana está aliada ao pagamento por produção acaba favorecendo especialmente os jovens do sexo masculino. Na opinião da entrevistada isso se dá porque são os homens os que têm um preparo físico melhor e mais apropriado para este tipo de trabalho. Para Ana, em geral as mulheres não possuem tanta força nem resistência física, e por isso acabavam obtendo menores índices de produtividade, e, consequentemente, salários mais baixos.

É interessante destacar aqui que tanto Maria como Ana relataram em suas entrevistas que eram trabalhadoras que não cortavam muita cana, e que tinham índices de produtividade abaixo dos demais colegas de trabalho. Ambas eram mães de

\footnotetext{
${ }^{4}$ Em função do compromisso de que nenhuma informação passível de identificar os sujeitos fosse divulgada, os nomes dos participantes referidos neste estudo foram alterados e substituídos por nomes fictícios, assim como os de todas as pessoas às quais eles se referiram nas entrevistas.
} 
família, e acabavam tendo que, além de trabalhar nos canaviais, cuidar de seus filhos e do trabalho doméstico após seu expediente. Com a dupla jornada de trabalho que desempenhavam, ficava extremamente difícil para as trabalhadoras cortarem uma grande quantia de cana ao longo de seu dia de trabalho nas usinas, uma vez que "Eu já chegava cansada para cortar cana, aí eu não conseguia cortar muito" (Ana). Não é difícil perceber que pelo fato de as cortadoras de cana receberem de acordo com o que trabalhavam, e pelo fato de elas não conseguirem cortar tanto, ambas acabavam recebendo um salário mensal extremamente baixo.

Isso acabou levando muitas mulheres a buscar outras formas de emprego remunerado que as ajudasse a complementar o ínfimo salário que recebiam nas usinas. Assim, a jornada semanal de trabalho das mesmas - além de contar com os seis dias da semana em que trabalham oito horas por dias nas usinas - é acrescida de outros dois períodos de trabalho adicionais: um período em que exercem outro tipo de atividade remunerada "fora de casa e fora da usina", como por exemplo, faxina nos dias em que não trabalham nos canaviais; e um período em que desempenham os serviços domésticos em suas próprias casas. $\mathrm{O}$ resultado disso é claro: para poderem sobreviver, as mulheres são obrigadas a trabalhar cada vez mais, e como contrapartida desta tripla jornada de trabalho as mesmas têm adoecido frequentemente, não somente física, mas também psicologicamente.

Mas, e o que aconteceu com as mulheres cortadoras de cana de outras usinas que não podiam contar com seus respectivos sindicatos para lhes assegurar suas vagas de trabalho? O que ocorreu com aqueles(as) que foram alijados(as) do trabalho no corte manual da cana devido ao processo de reestruturação produtiva pelo qual passou o setor sucroalcooleiro?

No que se refere especificamente às mulheres, em seu estudo Silva (2011a) demonstrou que as mesmas, quando não foram transferidas para trabalhar em outras culturas agrícolas (tais como laranja, café, tomate, cebola, etc.), foram sendo, aos poucos, destinadas a outras atividades/funções nos canaviais, tais como o 
plantio, a "bituca" e a recolha de pedras. Nas palavras de Silva (2011a):

Aí [nos canaviais] foi possível ainda identificar a segregação sexual do trabalho, na medida em que as mulheres foram sendo alijadas do corte manual da cana em favor dos jovens migrantes, e, assumindo funções mais desvalorizadas nos canaviais e também em outras culturas - frutas, cebola, tomate, feijão, milho -, onde predominam a circularidade e a rotatividade incessante dessa força de trabalho (SILVA, 2011a: 40).

Mas também houve casos de ex-cortadoras de cana que passaram a trabalhar como empregadas domésticas, faxineiras e cozinheiras nas cidades das usinas para qual trabalharam. Ainda de acordo com Silva (2011a):

Foram encontradas ex-trabalhadoras rurais que haviam cortado cana e, atualmente, em razão da segregação sexual do trabalho, por meio da qual essa atividade ficou reservada apenas aos homens, sobretudo aos jovens migrantes, estão trabalhando como domésticas na cidade de Ribeirão Preto. Um total de mais de 400 mulheres, transportadas em sete ônibus, viajavam diariamente de Guariba a Ribeirão Preto para o trabalho de faxineiras, cozinheiras, ajudantes de cozinha ou empregadas domésticas no ano de 2010 (SILVA, 2011a: 40).

Diferentemente de nossa pesquisa anterior (GUANAIS, 2010), em nossa pesquisa mais recente - realizada entre 2011 e 2013 - não foi possível localizar as mulheres cortadoras de cana nos canaviais nem sequer nos alojamentos coletivos das usinas. No momento das entrevistas, quando interrogados sobre a existência de mulheres cortando cana, a maioria dos trabalhadores rurais afirmava que nas usinas em que trabalhavam elas não existiam mais. De acordo com eles, as únicas mulheres que "circulavam" nas usinas eram as "meninas da limpeza", as responsáveis pela 
faxina dos alojamentos e das demais dependências das usinas. De todos os entrevistados, somente três trabalhadores mencionaram que ainda existiam algumas poucas mulheres trabalhando nos canaviais da Usina Costa Pinto, mas que essas desempenhavam outras funções, que não o corte de cana.

Essa última informação foi posteriormente confirmada pelo vice-presidente do Sindicato dos Trabalhadores Rurais de Piracicaba e Saltinho que, em sua entrevista, mencionou que ainda havia um número pequeno de mulheres trabalhando na usina em questão, mas que as mesmas não cortavam cana, mas sim faziam parte das "turmas de serviços gerais" ${ }^{5}$ da referida usina. Ainda de acordo com o sindicalista, essas poucas mulheres "sobrantes" não eram migrantes como os cortadores de cana e que, por isso, não residiam nos alojamentos coletivos, mas sim em suas próprias casas localizadas nos pequenos municípios próximos à Piracicaba.

Como é possível perceber, o processo de reestruturação produtiva e as reconfigurações pela quais passou o setor sucroalcooleiro trouxeram em seu bojo uma "nova" divisão sexual do trabalho ancorada nas antigas (e tão bem conhecidas) dicotomias: homens = resistência e força física; mulheres = fragilidade, delicadeza, cuidado e responsabilidade. Isso fez e continua fazendo até hoje com que os homens permaneçam sendo empregados pelas usinas como cortadores de cana e as mulheres passem a ocupar os demais cargos, sempre secundários e desvalorizados. Como decorrência desse processo, combinam-se dois resultados: "a masculinização e etnificação no corte da cana, e a feminização de certas atividades nos canaviais e em outras culturas agrícolas" (SILVA, 2011a: 31).

\footnotetext{
${ }^{5}$ As "turmas de serviços gerais" são responsáveis por fazer todas as atividades necessárias com exceção do plantio e do corte da cana. Para se ter um exemplo, os trabalhadores(as) que compõem as turmas de serviços gerais são responsáveis pela "bituca", pela "faxina" dos canaviais, pela abertura de eitos para as máquinas colheitadeiras, pelo recolhimento das pedras que ficam no meio dos canaviais, pela limpeza da parte industrial da usina, dentre outras tarefas.
} 
Antes de dar continuidade à discussão, é importante nesse momento definir o que entendemos por divisão sexual do trabalho. Aqui, nos amparamos na definição proposta por Danièle Kergoat (2009):

A divisão sexual do trabalho é a forma de divisão do trabalho social decorrente das relações sociais de sexo; essa forma é historicamente adaptada a cada sociedade (...) Essa forma de divisão social do trabalho tem dois princípios organizadores: o da separação (existem trabalhos de homens e outros de mulheres) e o da hierarquização (um trabalho de homem "vale" mais do que um de mulher) (KERGOAT, 2009: 67).

Como ficará claro a seguir, os dois princípios organizadores (separação e hierarquização) da divisão sexual do trabalho também estão presentes no setor sucroalcooleiro e no interior dos canaviais, trazendo consequências mais perversas às assalariadas rurais.

Em seu artigo, Silva (2011a) analisa cada tipo de função que as mulheres passaram a assumir a partir do momento em que foram excluídas do corte da cana. Plantio, "bituca"6, o trabalho

\footnotetext{
${ }^{6}$ Os trabalhadores(as) que são destinados(as) a ser bituqueiros(as) são os(as) responsáveis pelo recolhimento dos pedaços de cana que ficam ao longo do canavial depois de toda a cana ter sido colhida. De modo geral esse tipo de trabalhador(a) passa grande parte de sua jornada de trabalho agachado(a), com as costas curvas para recolher os pedaços de cana. Esse tipo de função é extremamente necessária às usinas, que a partir do trabalho dos(as) bituqueiros(as), evitam perdas significativas, que aconteciam por sobrar cana no eito sem ser pesada.
} 
na "perca"7, abertura de eitos ${ }^{8}$ e o recolhimento de pedras", são algumas dessas funções, as quais, por serem consideradas secundárias (isto é, menos importantes do que o corte da cana), estão dentre as mais desvalorizadas e mal remuneradas pelas usinas.

Como sabemos, por sua própria condição social, recaem sobre as mulheres estereótipos específicos, fazendo com que as mesmas de forma geral sejam vistas como mais "caprichosas", "responsáveis", "tolerantes" e "pacientes" do que os homens, e por isso acabam sendo preferidas para a realização de determinadas atividades $^{10}$. Nesse contexto, no interior dos canaviais cabem às mulheres as funções mencionadas acima (plantio, "bituca", etc.), justamente porque mais do que força ou resistência física ("atributos masculinos"), requerem capricho, cuidado, paciência

\footnotetext{
${ }^{7}$ As trabalhadoras da "perca" são aquelas que refazem o trabalho executado pelos homens durante o corte de cana. Tal atividade consiste em ficar rebaixando os "tocos" de cana que ficaram altos ou mal cortados (SILVA, 2011a).

8 "Abrir eito significa cortar as fileiras de cana que estão sobre as curvas de nível - sulcos feitos para a drenagem das águas fluviais - antes da utilização das máquinas, pois estas só cortam as canas em terras planas." (SILVA, 2011a:3).

${ }^{9}$ As "mulheres da pedra" são contratadas para retirar as pedras existentes no interior dos canaviais antes de iniciar o corte mecanizado. Tal atividade é bastante perigosa, já que muitos animais peçonhentos, tais como escorpiões e cobras, ficam escondidos sob as pedras e podem ferir qualquer pessoa que deles se aproximar.

${ }^{10}$ A esse respeito Silva (2011a) escreveu que "As mulheres são preferidas, segundo elas, porque são mais cuidadosas para pegar as bitucas deixadas pelos cortadores de cana. Elas afirmam que esse trabalho tem que ser feito mesmo por mulheres porque alguns homens cortadores de cana costumam 'deixar tudo bagunçado'. Então as mulheres da bituca 'arrumam' esta bagunça (...) esta distinção fica bastante acentuada na justificação do uso do trabalho feminino e masculino para a tarefa na bituca e corte de cana, respectivamente. A força física do homem no uso do facão e o cuidado feminino na organização e no recolhimento das canas que ficam espalhadas são as razões para a divisão de trabalho entre os sexos." (SILVA, 2011a: 35-36).
} 
e responsabilidade por parte daqueles(as) que as desempenham (SILVA 2011a).

Na maioria dessas funções, as mulheres passam grande parte da sua jornada de trabalho agachadas ou com as costas curvadas, já que a elas cabe o recolhimento das pedras ("mulheres da pedra") e dos pedaços de cana ("mulheres da bituca") que ficaram nos canaviais, e o rebaixamento daqueles "tocos" de cana que ficaram altos ou que foram mal cortados pelos homens cortadores de cana ("trabalhadoras da perca"). De acordo com Silva (2011a):

Tanto a atividade da bituca quanto à da perca exigem que as mulheres fiquem abaixadas durante toda a jornada de trabalho. São preferidas em razão dos estereótipos discriminatórios que afirmam que as mulheres são mais cuidadosas, enquanto os homens são mais relaxados (...) Ao realizarem a limpeza dos canaviais, as mulheres reproduzem os estereótipos sexistas vigentes na atividade canavieira. São duas funções desvalorizadas e precarizadas (SILVA, 2011a: 33-34) [grifos no original].

Como é possível perceber, essa divisão ${ }^{11}$ das atividades que fazem parte da cadeia produtiva da cana em "trabalhos de homens" e "trabalhos de mulheres" acaba não só reforçando os padrões e os estereótipos sexistas existentes na sociedade, mas também acentuando a segregação sexual do trabalho no interior dos canaviais. Mas, o que mais há por detrás dessa diferenciação e distinção entre "trabalhos de homens" e "trabalhos de mulheres"?

Tal como destacado por Kergoat (2009) na passagem citada anteriormente, além da separação entre os trabalhos de homens e de mulheres, essa forma específica de divisão social do trabalho

\footnotetext{
11 “Tais diferenças [biológicas] não causam a divisão sexual do trabalho (...) . O que há, reitera-se, é uma determinação social, que transforma as diferenças biológicas em causadoras desta divisão. Portanto, há, vis-à-vis as percepções, uma naturalização das diferentes tarefas exercidas por homens e mulheres." (SILVA, 1999: 183-184).
} 
também tem outro princípio organizador: a hierarquização, isto é, o trabalho de um homem tem mais valor quando comparado ao trabalho de uma mulher. E isso também fica bastante evidente quando analisamos o setor sucroalcooleiro. Ao separar e atribuir a cada sexo atividades e funções distintas, e por valorizar mais os trabalhos masculinos, as usinas conseguem remunerar de forma diferente seus(suas) trabalhadores(as). De acordo com as informações fornecidas pelo vice-presidente do Sindicato dos Trabalhadores Rurais de Piracicaba e Saltinho, as mulheres que trabalhavam nas "turmas de serviços gerais" da Usina Costa Pinto recebiam salários inferiores aos recebidos pelos homens cortadores de cana da mesma usina a despeito de trabalharem o mesmo número de dias e de horas na semana.

Mas, como sabemos, esse tipo de prática não é exclusividade do setor sucroalcooleiro, já que, de maneira geral, em quase todos os setores econômicos as mulheres acabam ocupando os cargos menos valorizados (e, portanto, mais mal pagos) do que aqueles que são ocupados pelos homens. Essa desigualdade nos salários entre homens e mulheres já foi objeto de investigação sociológica de muitos pesquisadores, e, dentre os vários estudos produzidos, destaca-se o de Maria Ignez Paulilo (1987), autora que procurou desvendar as causas da diferença de salários entre os homens e as mulheres no meio rural brasileiro.

Ao analisar a realidade de famílias de várias regiões rurais do Brasil ${ }^{12}$, Paulilo (1987) chama atenção para a valorização social do homem no meio rural como um todo. De acordo com a autora, independentemente das regiões pesquisadas, aquilo que ficou conhecido como trabalho "pesado" é sempre atribuído aos homens. Já as mulheres e crianças desempenham o chamado

\footnotetext{
${ }^{12}$ Em seu estudo, Paulilo (1987) analisou o sertão e o brejo paraibano (regiões onde predominam as lavouras de algodão e de cana e também a pecuária); algumas cidades do interior de São Paulo (onde predominam as fazendas de café) e a região sul de Santa Catarina (onde predomina a produção de fumo).
} 
trabalho "leve", o qual, justamente pelo fato de ser considerado "leve", é extremamente mal remunerado ${ }^{13}$ :

Trabalho "leve", feminino, é plantar, arrancar o mato miúdo e adubar. Para isso, as mulheres ganham a metade, ou menos, da diária de um homem, embora trabalhem o mesmo número de horas (...) Nenhum homem é contratado para fazer trabalho considerado feminino... (PAULILO, 1987: 66).

Em sua análise a autora destaca que os proprietários de terras de todas as regiões estudadas se valem dessa divisão sexual do trabalho para aumentar ainda mais os níveis de exploração sobre as mulheres. Para aquelas atividades em que a força física não traz maior rendimento (como o plantio e a adubagem), evitam a presença masculina para melhor caracterizá-la (e assim remunerá-la) como trabalho "leve". Apesar da sutiliza empregada na exploração da força de trabalho feminina, fica nítido que há casos em que as mulheres, a despeito de realizarem as mesmas tarefas que os homens, ganham menos. Assim, é a ideia do trabalho "leve" que explica o baixo preço pago pelos proprietários às trabalhadoras ${ }^{14}$ (PAULILO, 1987). Neste contexto, fica claro que

13 "Regiões distintas, culturas diferentes. Com um traço comum, a distinção entre trabalho 'leve' e 'pesado'. O primeiro, atribuição de mulheres e crianças. O segundo, incumbência masculina." (PAULILO, 1987: 66).

${ }^{14}$ De acordo com a Paulilo (1987), quando os fazendeiros foram interrogados sobre os motivos da distinção entre o emprego das mulheres e dos homens, justificaram que isso se dava porque o sustento da casa cabe ao marido, já que a mulher não precisa trabalhar o ano todo. Empregam-se mulheres apenas para "ajudar em casa", para ganharem "um dinheirinho a mais", o qual somente "complementará" o orçamento familiar. Pelo fato de não fazerem serviços pesados (como levantar cercas ou cuidar do gado), recebem somente $75 \%$ da diária masculina. 
o que determina em última instância o valor da diária ${ }^{15}$ é o sexo de quem a recebe.

Trabalho "leve" e "pesado" são, portanto, categorias que variam segundo o sexo do trabalhador e as condições de exploração da terra nas várias regiões agrícolas. Invariável é a convicção de que o trabalho feminino é mais barato. Essa constatação é frequente na literatura sociológica sobre a força de trabalho feminina nas cidades: as profissões consideradas femininas têm remuneração sempre inferior à daquelas consideradas masculinas. Mesmo em profissões iguais e cargos iguais, os dois sexos têm remunerações distintas (PAULILO, 1987: 68) ${ }^{16}$.

Mas afinal, por que se paga menos pela realização dos trabalhos "leves", isto é, por aqueles realizados por mulheres e crianças? De acordo com Paulilo (1987), a resposta para tal questão não deve ser buscada nas realidades específicas das regiões estudadas, já que essa situação decorre da valorização social do homem - rural ou urbano - enquanto "chefe de família" e responsável pela reprodução de seus "dependentes". Dessa forma o trabalho desses últimos fica em segundo plano, cabendo, nestes casos, uma remuneração que apenas "ajuda" na composição do orçamento familiar. "A conclusão, portanto, é clara: o trabalho é 'leve' (e a remuneração é baixa) não por suas próprias

\footnotetext{
${ }^{15}$ A "diária" é o valor pago aos(as) trabalhadores(as) referente a um dia de trabalho.

${ }^{16}$ A fala de uma entrevistada da autora deixa bem claro essa ideia, muitas vezes até mesmo aceita e naturalizada pelas próprias trabalhadoras. "A mulher ganha menos porque é mulher, né? $\mathrm{O}$ trabalho dela não vai com o do homem (...) O homem pega uma foice, broca mato, cava rego, abre valeta, traz água...e a mulher não vai fazer esse serviço. A mulher planta, a mulher semeia, a mulher alimpa, mas não pode fazer serviço mais pesado, fica sempre pra parte do homem. Aí, quer dizer, por isso o homem ganha mais..." (In: PAULILO, 1987: 64).
} 
características, mas pela posição que seus realizadores ocupam na hierarquia familiar" (PAULILO, 1987: 70).

\section{Breve consideração final}

Como mencionado na introdução, ainda que nossa pesquisa de campo tenha algumas particularidades quando comparada à desenvolvida por outros pesquisadores da área, no que se refere especificamente às mulheres assalariadas rurais, de forma geral os resultados obtidos se aproximam e vêm a corroborar aqueles já divulgados por pesquisas anteriores, tais como as de Maria Aparecida de Moraes Silva (1999 e 2011a e b). Contudo, antes de concluir o presente artigo, é interessante analisarmos mais um dado de campo que surgiu na pesquisa mais recente, realizada entre 2011 e 2013.

Como resultado do processo de expansão da mecanização da colheita de cana, a Usina Furlan (outra usina em que a pesquisa foi realizada) diminuiu significativamente o número de cortadores de cana empregados ao mesmo tempo em que aumentou a quantidade de vagas nas "turmas da diária". Muito similarmente ao que ocorria com a "turma de serviços gerais" da Usina Costa Pinto citada anteriormente, as "turmas da diária" da Furlan eram responsáveis por todas as atividades tidas como secundárias, tais como a "bituca", o recolhimento de pedras, a abertura de eitos para as máquinas, dentre outras. Contudo, nesta última empresa, somente homens trabalhavam nessas turmas e exerciam tais funções, o que comprova que a divisão sexual do trabalho não é invariável, mas sim adaptada a cada sociedade e momento histórico. Nas palavras de Kergoat (2009):

Portanto, não mais que as outras formas de divisão do trabalho, a divisão sexual do trabalho não é um dado rígido e imutável.Se seus princípios organizadores permanecem os mesmos, suas modalidades (concepção de trabalho reprodutivo, lugar das mulheres no trabalho mercantil etc.) variam fortemente no tempo e no espaço. Os dados da História e da Antropologia demonstraram- 
no amplamente: uma mesma tarefa, especificamente feminina numa sociedade ou ramo industrial, pode ser considerada tipicamente masculina em outros (...) Assim, problematizar em termos de divisão sexual do trabalho não remete a um pensamento determinista; ao contrário, trata-se de pensar a dialética entre invariantes e variações, pois, se supõe trazer à tona os fenômenos da reprodução social, esse raciocínio implica estudar ao mesmo tempo seus deslocamentos e rupturas, bem como a emergência de novas configurações que tendem a questionar a própria existência dessa divisão (KERGOAT, 2009: 68).

\section{Referências bibliográficas}

ALVES, F. J. da C. "Por que morrem os cortadores de cana?", Saúde e Sociedade, vol. 15, n. 3, 2006, pp. 90-98.

ARAÚJO, A. M. C. "Informalidade e relações de gênero", in GEORGES, I. P. H.; LEITE, M. de P. Novas configurações do trabalho e economia solidária. São Paulo: Annablume; Fapesp, 2009.

BUENO, J. D. De camponesas a operárias: narrativas do transitar feminino. Dissertação de mestrado. Programa de Pósgraduação em Sociologia. Centro de Educação e Ciências Humanas. UFSCar. São Carlos-SP, 2011.

CASTRO, M. G.; LAVINAS, L. "Do feminismo ao gênero: a construção de um objeto", in BRUSCHINI, C.; COSTA, A. de O. Uma questão de gênero. Rio de Janeiro: Rosa dos Tempos; São Paulo: Fundação Carlos Chagas, 1992.

D’INCAO, M. C. O "boia-fria": acumulação e miséria. Petrópolis: Vozes, 1976.

GUANAIS, J. B. No eito da cana, a quadra é fechada: estratégias de dominação e resistência entre patrões e cortadores de cana em Cosmópolis - SP. Dissertação de mestrado. Programa de Pós- 
graduação em Sociologia. Instituto de Filosofia e Ciências Humanas. UNICAMP. Campinas-SP, 2010.

Pagamento por produção, intensificação do trabalho e superexploração na agroindústria canavieira brasileira. Tese de Doutorado. Programa de Pós-graduação em Sociologia. Instituto de Filosofia e Ciências Humanas. UNICAMP. Campinas-SP, 2016.

IANNI, O. Origens agrárias do estado brasileiro. São Paulo: Ed. Brasiliense, 1984.

KERGOAT, D. Divisão sexual do trabalho e relações sociais de sexo. In. HIRATA, H. et al. Dicionário crítico do feminismo. São Paulo: Editora UNESP, 2009.

NOVAES, J. R. P. Heróis anônimos, Democracia viva, vol. 1, n. 36, 2007, pp. 58-67.

PAULILO, M. I. S. O peso do trabalho leve. In. Ciência Hoje, vol. 5, n. 28,1987 , pp. 64-70.

SAFFIOTI, H. Rearticulando gênero e classe social. In BRUSCHINI, C.; COSTA, A. de O. Uma questão de gênero. Rio de Janeiro: Rosa dos Tempos; São Paulo: Fundação Carlos Chagas, 1992.

SCOPINHO, R. A. Qualidade total, saúde e trabalho: uma análise em empresas sucroalcooleiras paulistas, $R A C$, vol. 4, n. 1, jan/ abr 2000, pp. 93-112.

. Controle social do trabalho no setor sucroalcooleiro: reflexões sobre o comportamento das empresas, do Estado e dos movimentos sociais organizados, Cadernos de Psicologia Social do Trabalho, vol. 7, 2004, pp. 11-29.

SILVA, M. A. de M. Errantes do fim do século. São Paulo: Ed. Unesp, 1999.

A morte ronda os canaviais paulistas. In. Revista da Associação Brasileira de Reforma Agrária, vol. 33, n. 2, 2006, pp. 111-114. 
|131|

Juliana Biondi Guanais

. O trabalho oculto nos canaviais paulistas. In. Perspectivas, vol. 39, n. 1, 2011a, pp. 11-46.

. De colona à boia-fria, in PRIORE, M. D. História das mulheres no Brasil. São Paulo: Contexto, 2011b.

Idéias - Rev. Inst. Filos. Ciênc. Hum. UNICAMP, v.7, n.1, p. 111-132, jan/jul. 2016 
|132 |

Reestruturação produtiva e divisão sexual do trabalho... 